\title{
Fetal growth restriction: aetiology, screening, diagnosis and management
}

\author{
Valsa Chathampadathil Augusthy*
}

Department of Obstetrics \& Gynaecology, Pushpagiri Medical College Hospital, Thiruvalla, Kerala, India

Received: 23 September 2015

Accepted: 30 October 2015

\author{
*Correspondence: \\ Dr. Valsa Chathampadathil Augusthy, \\ E-mail: drvalsa777@gmail.com
}

Copyright: $\odot$ the author(s), publisher and licensee Medip Academy. This is an open-access article distributed under the terms of the Creative Commons Attribution Non-Commercial License, which permits unrestricted non-commercial use, distribution, and reproduction in any medium, provided the original work is properly cited.

\begin{abstract}
Foetal growth restriction (FGR) is a pathological condition that refers to a foetus that fails to reach his/her genetically predetermined growth potential. FGR remains a leading contributor to perinatal mortality and morbidity and metabolic syndrome in later life. The purpose of this review is to provide the summary statements of the aetiology of FGR and to establish a framework for screening, diagnosis, and management of pregnancies affected with foetal growth restriction. For this study, published literature was retrieved through searches of PubMed (Medline), Highwire, Google Scholar, Scopus, Cochrane Database of Systematic Reviews. Conference/Seminar proceedings, textbooks, previously published systematic reviews, controlled clinical trials, high quality prospective and retrospective observational studies, research articles and unpublished studies were also used for this study. The identification of FGR begins with assessment of maternal, foetal, placental and environmental risk factors and the diagnosis is made by Ultrasound biometry examination. Functional assessment of placental and foetal circulation by Doppler velocimetry and blood flow volume, together with computerized assessment of foetal heart rate variability, are key examinations in early and late FGR to assess severity of the disease and monitor foetal wellbeing. Appropriate timing of delivery in early FGR might change the outcome, and appropriate monitoring in late and term FGR might avoid unnecessary interventions.
\end{abstract}

Keywords: Foetal growth restriction, Foetal abdominal circumference, Doppler velocimetry, Screening, Diagnosis, Management

\section{INTRODUCTION}

Fetal growth restriction (FGR) is a pathological condition that refers to a fetus that fails to reach his/her genetically predetermined optimal growth potential and constitutes a major clinical and public health problem, mainly in the developing world. Traditionally, an estimated foetal weight (EFW) or abdominal circumference (AC) below the 10th percentile raises concerns over suboptimal intrauterine growth, however the distinction between normal and pathologic growth often cannot reliably be made at this arbitrary cut-off. In addition, approximately $70 \%$ of foetuses below the $10^{\text {th }}$ percentile will have a normal perinatal outcome. ${ }^{1}$ The risk of adverse outcome is proportional to the degree of growth restriction with those below the 3rd percentile and/ or abnormal umbilical artery Doppler measurements at greatest risk of morbidity or mortality. ${ }^{2}$ In addition, analysis of foetal growth trajectories has been identified as an important factor in the differentiation between physiological small-forgestational age (SGA) and pathological intrauterine growth restriction. ${ }^{3}$

Fetal growth restriction is associated with increased perinatal mortality and morbidity due to higher risk of intrauterine fetal demise (IUFD), intrapartum morbidity, and increased rate of iatrogenic prematurity (before 34 weeks of gestation). ${ }^{4,5}$ Besides the short-term 
complications such as polycythemia, hypoglycemia, hypothermia, and respiratory difficulties due to induced prematurity, FGR newborns have a higher risk of longterm complications such as developmental delay, and behavioral dysfunctions. ${ }^{6,7}$ Moreover, an increasing number of reports suggests the causative link between FGR and metabolic syndrome in adulthood. ${ }^{8}$

Historically, foetal growth restriction has been categorized as symmetric or asymmetric. Symmetric foetal growth restriction refers to foetuses with equally poor growth velocity of the head, the abdomen and the long bones. Asymmetric foetal growth restriction refers to infants whose head and long bones are spared compared with their abdomen and viscera. ${ }^{9}$ The clinical observations made by Dashe et al found that among small-for-gestational age foetuses with no anatomic abnormalities, only those that were asymmetrically small were associated with increased pregnancy-induced maternal hypertension before 32 weeks and caesarean delivery for abnormal heart rate patterns compared with those of foetuses average for gestational age. ${ }^{10}$ Additionally, asymmetric small-for-gestational age foetuses sustained more adverse neonatal composite outcomes compared to symmetric small-for-gestational age or average for gestational age foetuses.

\section{AETIOLOGY}

It is important to identify etiological factors in FGR because this directs the managing physician to an early diagnosis. Conditions that result in foetal growth restriction broadly consist of maternal, foetal, placental, and environmental disorders.

\section{Maternal factors}

Women at extremes of reproductive age $(<16$ years, $>40$ years), are at increased risk for FGR. ${ }^{11}$ Social factors, such as ethnicity, poverty status, age at menarche, maternal height, and net maternal weight gain have an independent effect on birth weight in adolescent mothers. ${ }^{12}$ Maternal weight at birth, low pre-pregnancy weight, and poor weight gain during pregnancy are positively associated with increase in FGR. ${ }^{13,14}$ Women with lower socioeconomic status commonly have poor nutritional status, maternal anaemia, and poor prenatal care and substance abuse problem, which affect foetal growth. Maternal heavy cigarette smoking and excess amount of alcohol consumption throughout the pregnancy, especially in third trimester, is associated with FGR. ${ }^{15-18}$ The use of illicit drugs like heroin and cocaine and exposure to various medications, such as warfarin, anticonvulsants, antineoplastic agents can result in FGR. ${ }^{19-21}$

Maternal disease and systemic conditions such as reduced uteroplacental blood flow, reduced oxygen-carrying capacity, or decreased nutrition to the fetus, chronic hypertension, preeclampsia, pregestational diabetes, chronic renal insufficiency, systemic lupus erythematous (SLE), antiphospholipid syndrome, renal diseases, autoimmune diseases and acquired thrombophilia, chronic maternal hypoxemia due to pulmonary disease, cardiac disease have been associated with FGR. ${ }^{22-25}$ maternal malnutrition, protein deficiency and gastrointestinal conditions can cause lower birth weight because of decreased nutrition to the foetus. Other maternal causes include uterine factor, maternal periodontal disease, and genetic conditions, such as angiotensinogen gene mutations. ${ }^{26-28}$

\section{Foetal factors}

Fetal causes are less common in FGR and include genetic causes, congenital malformations, foetal infection, or other causes, including multiple pregnancies. Genetic causes include various abnormalities such as chromosomal abnormalities, autosomal abnormalities, ring chromosome structural alterations and single gene disorders. Congenital malformations, including congenital heart disease, diaphragmatic hernia, abdominal wall defects, renal agenesis or dysplasia, anencephaly, and single umbilical artery, are associated with FGR. ${ }^{29-32}$ Common infections accounts for FGR foetuses are viral (rubella, cmv, herpes, varicella, herpes zoster, HIV) parasitic infections (toxoplasmosis, syphilis, malaria) and bacterial infections (chlamydia, mycoplasma, listeria, and tuberculosis). ${ }^{33,34}$ Other viral, parasitic, and bacterial infections are associated with direct cell damage, or transplacental passage causing foetal infection, or placental vascular insufficiency. Multiple pregnancies and the risk of fetal growth restriction depend on a variety of factors such as chorionicity, number of fetuses, presence of congenital anomaly, umbilical cord abnormalities, unequal placenta, presence of twin transfusion syndrome, conjoint twin, and acardia. ${ }^{35-37}$

\section{Placental factors}

Normal placental development and functional integrity are essential for normal fetal growth. There is extensive evidence demonstrating that placental insufficiency accounts for FGR. ${ }^{38,39}$ The relative decrease in placental mass and function and immunological disturbances at the maternal-fetal interface can result in the development of FGR $^{40}$ placental causes of FGR include placental abruption, placenta accreta, placental infarction, placental villous obliteration, circumvallate placenta, placental hemangioma, placenta previa, placental mosaicism, single umbilical artery, and velamentous cord insertion. $^{41,42}$

\section{Environmental factors}

Environmental risk factors for FGR may include exposure to radiation, chemicals and use of drugs, such as the anticonvulsants (phenytoin and trimethadione), warfarin, and heroin etc. Environmental risk factors such 
as high altitude areas which are exposed to chronic hypoxia cause FGR. ${ }^{43,44}$

\section{Screening and diagnosis}

Effective screening for intrauterine growth restriction requires patient's history, physical examination, and general laboratory tests during routine antenatal care. Accurate dating is a prerequisite for pregnancy care and the tracking of foetal growth. This should be established from a careful history and correlated with the results of early ultrasound examinations in the first or second trimester. Foetal growth is estimated during routine antenatal care using symphysis-fundal height (SFH) measurement followed by the foetal ultrasound examination (foetal biometry). ${ }^{45-47}$ Measurements of foetal head circumference (HC), abdominal circumference (AC) and femur length (FL) allow for the comparison of individual growth and local reference values or customized growth charts. ${ }^{48}$ Beside the comparison with standard growth curves and an auxologic assessment of head to abdomen proportion, these measurements allow the calculation of estimated foetal weight (EFW). ${ }^{49,50}$ The validity of both symphysisfundal height (SFH) determined by clinical examination and estimated foetal weight (EFW) determined by ultrasound to identify FGR foetuses may be improved though customized standards that are designed to identify foetuses that measure $<10$ th percentile of their expected genetic growth potential. ${ }^{51,52}$ This approach adjusts the growth curve percentiles for anthropomorphic variables such as maternal height, weight, parity, and foetal sex. ${ }^{53}$ evidence from controlled, non-randomized trials supports this approach. ${ }^{54,55}$ in addition, customized growth percentiles are better correlated with adverse pregnancy events and reduce the frequency of additional testing because of false-positive screening information. ${ }^{56-58}$ ultrasound assessment, using uterine artery doppler and placental morphology, is of value to distinguish a subset of pregnancies at high risk of early severe FGR. ${ }^{59-61}$ In women with risk factors for intrauterine growth restriction, uterine artery doppler screening at 19 to 23 weeks may identify pregnancies at risk of antepartum stillbirth and preterm delivery due to intrauterine growth restriction and placental disease. ${ }^{62}$ In pregnancies in which intrauterine growth restriction due to uteroplacental vascular insufficiency is diagnosed, maternal surveillance for the development of severe preeclampsia with adverse features is warranted. ${ }^{63,64}$ Evaluation of placental function by umbilical artery doppler is a clinical standard to distinguish between SGA and FGR. ${ }^{65,66}$

\section{MANAGEMENT}

When intrauterine growth restriction is diagnosed, surveillance should be initiated. Serial ultrasound estimation of foetal weight (every 2 weeks), along with umbilical artery doppler studies should be initiated. If available, a placental assessment and other doppler studies such as middle cerebral artery, umbilical vein, and ductus venosus can be performed. Increased frequency of surveillance may be required. ${ }^{67}$ if foetal growth starts to plateau, amniotic fluid index starts to decline, or foetal tone or gross movements are diminished or absent, then more intensive surveillance (e.g., 2 to 3 times per week) or admission to hospital and delivery planning is required. Abnormal umbilical cord doppler (e.g., absent or reversed end-diastolic flow) in the presence of intrauterine growth restriction is an ominous finding that requires intervention and possible delivery.

If delivery was not indicated prior to 37 weeks in a patient diagnosed with intrauterine growth restriction, expectant management with close foetal and maternal surveillance versus delivery should be discussed after 37 weeks. ${ }^{68}$ If growth continues along growth curve: conduct weekly biophysical profile and umbilical artery doppler; add growth every 2 weeks; consider delivery near term ( 38 to 40 weeks) if no other issues.

If growth plateaus or stops $<34$ weeks: administer corticosteroids; increase surveillance to 2 to 3 times per week; consider hospitalization; consider maternal-foetal medicine consultation; consider neonatal consultation. FGR foetus < 34weeks with abnormal umbilical artery doppler studies, consider MCA and dv studies. Delivery is recommended when umbilical artery, MCA, and dv doppler studies becomes abnormal and NST is abnormal. NST can be used selectively if the BPP is abnormal. If abnormal doppler studies (e.g., absent or reversed enddiastolic flow) and normal BPP and NST: continue intensive monitoring with BPP and umbilical dopplers 2 to 3 times per week; deliver if BPP or umbilical dopplers worsen or if $\mathrm{MCA} / \mathrm{dv}$ are abnormal. If the period of gestation is $>34$ weeks and the AFV and DVP, BPP, and doppler studies are normal: conduct weekly surveillance and discuss delivery or on-going monitoring after 37 weeks. If abnormal fluid (AFV $<5 \mathrm{~cm}$ or DVP $<2 \mathrm{~cm}$ ), BPP, and/or doppler studies: consider delivery. ${ }^{69}$

\section{CONCLUSIONS}

Management of FGR remains one of the main challenges for the obstetricians, both for the complexities of management of severe early FGR and for the diagnostic difficulties in late and term FGR. Ultrasound biometry examination is crucial for an accurate diagnosis of FGR. Pregnancies at risk of FGR should be considered for longitudinal ultrasound monitoring beyond the routine ultrasound screening at 20 weeks of gestation. Functional assessment of placental and foetal circulation by Doppler velocimetry and blood flow volume, together with computerized assessment of foetal heart rate variability, are key examinations in early and late FGR to assess severity of the disease and monitor foetal wellbeing. Appropriate timing of delivery in early FGR might change the outcome, and appropriate monitoring in late and term FGR might avoid unnecessary interventions. Following delivery, pathological 
examination of the placenta may provide key insights into the underlying cause. Maternal thrombophilia testing and a review of the results of both the placental pathology and pertinent neonatal investigations may refine the presumptive cause of FGR that could alter the management plan in a subsequent pregnancy. Further research is needed to illuminate the preventive strategies and treatment strategies to assist the growth-restricted foetus.

\section{Abbreviations}

AC: Abdominal circumference

EFW: Estimated foetal weight

FGR: Foetal growth restriction

FL: Femur length

HC: Head circumference

IUFD: Intrauterine foetal demise

SFH: Symphysis fundal height

SGA: Small-for-gestational age

SLE: Systemic lupus erythematous

Funding: No funding sources

Conflict of interest: None declared

Ethical approval: Not required

\section{REFERENCES}

1. Lees C, Baumgartner H. Perinatal morbidity and mortality in early-onset fetal growth restriction: cohort outcomes of the trial of randomized umbilical and fetal flow in Europe. Ultrasound Obstet Gynecol. 2013;42:400-8.

2. Unterscheider J, Daly S, Geary MP, Kennelly MM, McAuliffe FM, O'Donoghue K, et al. Optimizing the Definition of Intrauterine Growth RestrictionResults of the Multicenter Prospective PORTO Study. Am J Obstet Gynecol. 2013;208(4):290-6.

3. Barker ED, McAuliffe FM, Alderdice F, Unterscheider J, Daly S, Geary MP, et al. The Role of Growth Trajectories to Identify Fetal Growth Restriction. Obstet Gynecol. 2013;122:248-54.

4. Manning E, Corcoran P, Meaney S, Greene RA. On behalf of the Perinatal Mortality Group: Perinatal Mortality in Ireland Annual Report 2011. NPEC, Cork, 2013.

5. Bernstein I, Gabbe SG, Reed KL. In: Gabbe SG et al., editors. Intrauterine growth restriction. in Obstetrics: Normal and Problem Pregnacies. New York: Churchill Livingston, 2002.

6. Hernandez-Andrade E, Stampalija T, Figueras F. Cerebral blood flow studies in the diagnosis and management of intrauterine growth restriction. Curr Opin Obstet Gynecol. 2013;25(2):138-44.

7. Villar J, de Onis M, Kestler E, Bolanos F, Cerezo R, Bernedes $\mathrm{H}$. The differential neonatal morbidity of the intrauterine growth retardation syndrome. Am J Obstet Gynecol. 1990;163:151-7.
8. Varvarigou AA. Intrauterine growth restriction as a potential risk factor for disease onset in adulthood. $\mathbf{J}$ Pediatr Endocrinol Metab. 2010;23:215-24.

9. Verburg BO, Steegers EA, De RM, Snijders RJ, Smith E, Hofman A et al. New charts for ultrasound dating of pregnancy and assessment of fetal growth: longitudinal data from a population-based cohort study. Ultrasound Obstet Gynecol. 2008;31(4):38896.

10. Dashe JS, McIntire DD, Lucas MJ, Leveno KJ. Effects of symmetric and asymmetric fetal growth on pregnancy outcomes. Obstet Gynecol. 2000;96(3):321-27.

11. Lee KS, Ferguson RM, Corpuz M, Gartner LM. Maternal age and incidence of low birth weight at term: a population study. Am J Obstet Gynecol. 1988;158(1):84-9.

12. Strobino DM, Ensminger ME, Kim YJ, Nanda J. Mechanisms for maternal age differences in birth weight. Am J Epidemiol. 1995;142(5):504-14.

13. Wen SW, Goldenberg RL, Cutter GR, et al. Intrauterine growth retardation and preterm delivery: prenatal risk factors in an indigent population. Am J Obstet Gynecol. 1990;162:213-8.

14. Berghella V. Prevention of recurrent fetal growth restriction. Obstet Gynecol. 2007;110(4):904-12.

15. Lieberman E, Gremy I, Lang JM, Cohen AP. Low birth weight at term and the timing of fetal exposure to maternal smoking. Am J Public Health. 1994;84(7):1127-31.

16. Wen SW, Goldenberg RL, Cutter GR, Hoffman HJ, Cliver SP, Davis RO, et al. Smoking, maternal age, fetal growth and gestational age at delivery. Am J Obstet Gynecol. 1990;162:213-53.

17. Shu XO, Hatch MC, Mills J. Maternal smoking, alcohol drinking, caffeine consumption, and fetal growth: results from a prospective study. Epidemiology. 1995;6:115-20.

18. Mills JL, Graubard BI, Harley EE. Maternal alcohol consumption and birth weight: How much drinking during pregnancy is safe? JAMA 1984;252:1875.

19. Naeye RL, Blanc W, Leblanc W, Khatamee MA. Fetal complications of maternal heroin addiction: abnormal growth, infections and episodes of stress. J Pediatr. 1973;83:1055-61.

20. Fulroth R, Phillips B, Durand DJ. Perinatal outcome of infants exposed to cocaine and/or heroin in utero. Am J Dis Child. 1989;143:905-10.

21. Little BB, Snell LM. Brain growth among fetuses exposed to cocaine in utero: Asymmetrical growth retardation. Obstet Gynecol. 1991;77:361.

22. Hendrix N, Berghella V. Non-placental causes of intrauterine growth restriction. Semin Perinatol. 2008;32(3):161-5.

23. American College of Obstetricians and Gynecologists. Intrauterine growth restriction. Practice Bulletin no. 12, 2000, Washington DC. http://www.acog.org. Accessed 28 December 2014.

24. Reeves S, Galan HL. Fetal growth restriction. In: Berghella V, editor. Maternal-fetal evidence based 
guidelines. 2nd ed. London: Informa Health Care. 2012:329-44.

25. Baschat AA, Galan HL, Gabbe SG. Intrauterine growth restriction. In: Gabbe SG, Neibyl JR, Simpson JL, editors. Obstetrics normal and problem pregnancies. Philadelphia: Elsevier. 2012:706-41.

26. Klatsky PC, Tran ND, Caughey AB, Fujimoto VY. Fibroids and reproductive outcomes: a systematic literature review from conception to delivery. Am J Obstet Gynecol. 2008;198:357-66.

27. Cooney MJ, Benson CB, Doubilet PM. Outcome of pregnancies in women with uterine duplication anomalies. J Clin Ultrasound. 1998;26(1):3-6.

28. Khader YS, Ta'ani Q. Periodontal diseases and the risk of preterm birth and low birth weight: a metaanalysis. J Periodontol. 2005;76(2):161-5.

29. Baschat AA, Galan HL, Gabbe SG. Intrauterine growth restriction. In: Gabbe SG, Neibyl JR, Simpson JL, editors. Obstetrics normal and problem pregnancies. Philadelphia: Elsevier. 2012:706-41.

30. Hendrix N, Berghella V. Non-placental causes of intrauterine growth restriction. Semin Perinatol. 2008;32(3):161-5.

31. Lin CC, Santolaya-Forgas J. Current concepts of fetal growth restriction: part I. Causes, classification, and pathophysiology. Obstet Gynecol. 1998;92(6):1044-55.

32. Khoury MJ, Erickson JD, Cordero JF, McCarthy BJ. Congenital malformations and intrauterine growth retardation: a population study. Pediatrics. 1988;82(1):83-90.

33. Hendrix N, Berghella V. Non-placental causes of intrauterine growth restriction. Semin Perinatol. 2008;32(3):161-5.

34. Divon MY, Ferber A. Overview of causes and risk factors for fetal growth restriction In: Lockwood CJ, Barss VA (eds) UpToDate http://www.uptodate.com. Accessed 28 December 2014.

35. Divon MY, Weiner Z. Ultrasound in twin pregnancy. Semin Perinatol. 1995;19:404-12.

36. D'Alton ME, Simpson LL. Syndromes in twins. Semin Perinatol. 1995;19:375-86.

37. Miller J, Chauhan SP, Abuhamad AZ. Discordant twins: diagnosis, evaluation and management. Am J Obstet Gynecol. 2012;206(1):10-20.

38. Khong TY, De Wolf F, Robertson WB, Brosens I. Inadequate maternal vascular response to placentation in pregnancies complicated by preeclampsia and by small for- gestational age infants. Br J Obstet Gynaecol. 1986;93(10):1049-59.

39. Pijnenborg R, Vercruysse L, Hanssens M. The uterine spiral arteries in human pregnancy: facts and controversies. Placenta. 2006;27(9):939-58.

40. Baschat AA, Galan HL, Gabbe SG. Intrauterine growth restriction. In: Gabbe SG, Neibyl JR, Simpson JL, editors. Obstetrics normal and problem pregnancies. Philadelphia: Elsevier. 2012:706-41.

41. Laurini R, Laurin J, Marsal K. Placental histology and fetal blood flow in intrauterine growth retardation. Acta Obstet Gynecol Scand. 1994;73:529-34.

42. Wilkins-Haug L, Roberts DJ, Morton CC. Confined placental mosaicism and intrauterine growth retardation: a case control analysis of placentas at delivery. Am J Obstet Gynecol. 1995;172:44-50.

43. Galan HL, Rigano S, Radaelli T, et al. Reduction of subcutaneous mass, but not lean mass, in normal fetuses in Denver, Colorado. Am J Obstet Gynecol. 2001;185:839-44.

44. Kametas NA, McAuliffe F, Krampl E, et al. Maternal cardiac function during pregnancy at high altitude. BJOG. 2004;111:1051-8.

45. Calvert JP, Crean EE, Newcombe RG, Pearson JF. Antenatal screening by measurement of symphysisfundus height. Br Med J 1982;285:846-9.

46. Persson B, Stangenberg M, Lunell NO, Brodin U, Holmberg NG, Vaclavinkova V. Prediction of size of infants at birth by measurement of symphysis fundus height. Br J Obstet Gynaecol. 1986;93:206-11.

47. Campbell S, Thoms A. Ultrasound measurement of the fetal head to abdomen circumference ratio in the assessment of growth retardation. $\mathrm{Br} \mathrm{J}$ Obstet Gynaecol. 1977;84:165-74.

48. Figueras F, Gardosi J. Should we customize fetal growth standards? Fetal Diagn Ther. 2009;25(3):297303.

49. Shepard MJ, Richards VA, Berkowitz RL, Warsof SL, Hobbins JC. An evaluation of two equations for predicting fetal weight by ultrasound. Am J Obstet Gynecol. 1982;142(1):47-54.

50. Hadlock FP, Harrist RB, Sharman RS, Deter RL, Park SK. Estimation of fetalweightwith the use of head, body, and femur measurements - a prospective study. Am J Obstet Gynecol. 1985;151(3):333-7.

51. Gardosi J. Customized fetal growth standards: rationale and clinical application. Semin Perinatol. 2004;28:33-40.

52. Ego A, Subtil D, Grange G, et al. Customized versus population-based birth weight standards for identifying growth restricted infants: a French multicenter study. Am J Obstet Gynecol. 2006;194:1042-9.

53. Gardosi J, Chang A, Kalyan B, Sahota D, Symonds EM. Customized antenatal growth charts. Lancet. 1992;339:283-7.

54. Clausson B, Gardosi J, Francis A, Cnattingius S. Perinatal outcome in SGA births defined by customized versus population-based birth weight standards. BJOG 2001;108:830-4.

55. Gardosi J, Francis A. Controlled trial of fundal height measurement plotted on customized antenatal growth charts. Br J Obstet Gynaecol. 1999;106:30917.

56. Clausson B, Gardosi J, Francis A, Cnattingius S. Perinatal outcome in SGA births defined by customised versus population-based birthweight standards. BJOG. 2001;108:830-4.

57. Sciscione AC, Gorman R, Callan NA. Adjustment of birth weight standards for maternal and infant 
characteristics improves the prediction of outcome in the small-for-gestational-age infant. Am J Obstet Gynecol. 1996;175:544-7.

58. De Jong CL, Gardosi J, Dekker GA, Colenbrander GJ, van Geijn HP. Application of a customized birth weight standard in the assessment of perinatal outcome in a high risk population. $\mathrm{Br} \mathrm{J}$ Obstet Gynaecol. 1998;105:531-5.

59. Alkazaleh F, Chaddha V, Viero S. Second-trimester prediction of severe placental complications in women with combined elevations in alphafetoprotein and human chorionic gonadotrophin. Am J Obstet Gynecol. 2006;194:821-7.

60. Toal M, Chaddha V, Windrim R, Kingdom J. Ultrasound detection of placental insufficiency in women with elevated second trimester serum alphafetoprotein or human chorionic gonadotropin. J Obstet Gynaecol Can. 2008;30:198-206.

61. Proctor LK, Toal M, Keating S, Chitayat D, Okun N, Windrim RC, et al. Placental size and the prediction of severe early-onset intrauterine growth restriction in women with low pregnancy-associated plasma protein-A. Ultrasound Obstet Gynecol. 2009;34:27482.

62. Toal M, Chan C, Fallah S, Alkazaleh F, Chaddha V, Windrim RC, et al. Usefulness of a placental profile in high-risk pregnancies. Am J Obstet Gynecol. 2007;196:363-7.

63. Franco C, Walker M, Robertson J, Fitzgerald B, Keating S, McLeod A, et al. Placental infarction and thrombophilia. Obstet Gynecol. 2011;117:929-34.
64. Mitani M, Matsuda Y, Makino Y, Akizawa Y, Ohta H. Clinical features of fetal growth restriction complicated later by preeclampsia. J Obstet Gynaecol Res. 2009;35:882-7.

65. The Society of Obstetricians and Gynaecologists of Canada. Clinical practice guidelines. The use of fetal Doppler in obstetrics. J Obstet Gynecol Can. 2003;25:601-7.

66. American College of Obstetricians and Gynecologists Committee on Obstetric Practice. Utility of antepartum umbilical artery Doppler velocimetry in intrauterine growth restriction. ACOG committee opinion no. 188, October 1997. Int J Gynaecol Obstet. 1997;59:269-70.

67. Baschat AA, Cosmi E, Bilardo CM, Wolf H, Berg C, Rigano $\mathrm{S}$, et al. Predictors of neonatal outcome in early-onset placental dysfunction. Obstet Gynecol 2007;109:253-61.

68. Royal College of Obstetricians and Gynaecologists. Green-top guideline No. 31: The investigation and management of the small for gestational age fetus. 2nd ed. UK: RCOG, 2013.

69. Lausman A, Kingdom J. Intrauterine growth restriction: screening, diagnosis, and management. J Obstet Gynaecol Can. 2013;35(8):741-8.

Cite this article as: Augusthy VC. Fetal growth restriction: aetiology, screening, diagnosis and management. Int J Reprod Contracept Obstet Gynecol 2015;4:1672-7. 